\title{
Androgen regulated TRPM8 expression: A potential mRNA marker for metastatic prostate cancer detection in body fluids
}

\author{
V. UMA BAI ${ }^{1}$, SHALINI MURTHY ${ }^{1}$, KANNAGI CHINNAKANNU ${ }^{1}$, FRED MUHLETALER ${ }^{1}$, SHEELA TEJWANI ${ }^{2}$, \\ EVELYN R. BARRACK ${ }^{1}$, SAHN-HO KIM ${ }^{1}$, MANI MENON ${ }^{1}$ and G. PREM VEER REDDY ${ }^{1}$
}

${ }^{1}$ Vattikuti Urology Institute and ${ }^{2}$ Division of Hematology and Oncology, Henry Ford Hospital, Detroit, MI 48202, USA

Received October 9, 2009; Accepted November 18, 2009

DOI: 10.3892/ijo_00000518

\begin{abstract}
Identification of sensitive and specific biomarkers for early detection and prognosis of prostate cancer is essential for timely and appropriate treatment of the disease in individual patients. We identified an RNA transcript with sequence homology to TRPM8 (melastatin-related transient receptor potential member 8 ) that was overexpressed in tumor vs. patient-matched non-tumor prostate tissues by RT-PCR differential display (DD). Semi-quantitative RT-PCR analysis revealed that TRPM8 levels were higher in tumor than in non-tumor tissue from 31 of $40(>75 \%)$ patients examined. Overexpression of TRPM8 was independent of changes in androgen receptor (AR) mRNA levels in tumor tissue. However, in studies with established cell lines, TRPM8 expression was detectable only in AR-positive, but not in AR-negative cells, and it was suppressed by steroid deprivation or anti-androgen bicalutamide (Casodex) treatment, suggesting the requirement of AR activity for TRPM8 expression in prostate cancer cells. TRPM8 mRNA was also detected in body fluids of men. Most importantly, its levels were significantly higher $(\mathrm{p}<0.001, \mathrm{n}=18)$ in urine and blood of patients with metastatic disease than in those of healthy men. However, there was no significant difference $(\mathrm{p}>0.05$, $\mathrm{n}=10$ ) in its levels between prostate cancer patients with localized disease and healthy men. Together, these studies demonstrate that TRPM8 expression is androgen regulated in prostate cancer cells and that, while tissue TRPM8 mRNA levels can be used for detection of prostate cancer, urine and blood TRPM8 mRNA levels may prove to be useful for distinguishing metastatic disease from clinically localized prostate cancer at the time of diagnosis.
\end{abstract}

Correspondence to: Dr G. Prem Veer Reddy, Henry Ford Health System, 1 Ford Place, 2D, Detroit, MI 48202, USA

E-mail: preddy1@hfhs.org

Key words: prostate cancer, TRPM8, differential display, urine, blood, detection and prognosis, androgen receptor, cell synchronization

\section{Introduction}

Prostate cancer is the most commonly diagnosed non-skin cancer and the second most common cause of cancer-related deaths in men in the USA (1). Although clinically-diagnosed prostate cancer affects 1 in 6 American men (1), approximately 1 in 3 has histological evidence of prostate cancer at $>50$ years of age (2). Thus, while the disease is highly prevalent its aggressiveness varies among individuals. Furthermore, the disease recurs in $25 \%$ of men who have undergone radical prostatectomy for clinically organ-confined prostate cancer (3), suggesting spread of the disease beyond the primary site in these patients. Currently, there are no markers available to distinguish patients with localized cancer from those with metastatic disease at the time of diagnosis. Therefore, there is a need for biomarkers to detect prostate cancer in its early stage and also to distinguish disease that is truly organ-confined from that which has metastasized, in order to administer a more aggressive treatment at the time of initial diagnosis.

Currently, prostate cancer detection starts with a digital rectal examination (DRE) and measurement of serum PSA levels. PSA is expressed normally in the prostate and men with serum PSA levels $>4 \mathrm{ng} / \mathrm{ml}$ are considered to be at risk for prostate cancer. However, PSA levels $>4 \mathrm{ng} / \mathrm{ml}$ can also occur in men with benign prostatic hyperplasia (BPH) or prostatitis. Thus, only $25 \%$ of men with an elevated PSA have biopsyproven prostate cancer (4). Conversely, about $15 \%$ of men with a serum PSA $\leq 4 \mathrm{ng} / \mathrm{ml}$ have biopsy-proven prostate cancer (5). Thus, while serum PSA is helpful as a sensitive indicator of persistent disease and as a marker of treatment response, its usefulness as a screening tool for detection and treatment of prostate cancer is controversial (6). In addition, patients with a negative biopsy despite an elevated serum PSA, and patients with low risk prostate cancer, need to be monitored by annual prostate biopsy (7). Repeat biopsy procedures may have undesirable side effects such as infection and urinary retention (8). Therefore, there is a need for sensitive and specific biomarkers to diagnose prostate cancer using easily obtainable body fluids such as urine and blood.

In recent years a variety of genome screening technologies, such as cDNA microarrays (9), oligonucleotide microarrays (10), serial analysis of gene expression (SAGE) (11) and comparative genomic hybridization (12), have been applied 
to prostate tumor tissues and cell lines with a hope to identify molecular markers that are more sensitive and specific than serum PSA for prostate cancer detection and progression. These technologies have identified a handful of blood or tissuebased markers which correlate with disease activity, disease aggressiveness, and/or treatment efficacy (12-14). Very few of these markers are undergoing clinical validation.

In the present study we identified an RNA transcript that is overexpressed in tumor as compared to patient-matched nontumor prostate tissue from clinically localized prostate cancer patients by using an RT-PCR differential display (DD) technique $(15,16)$. This transcript exhibited $100 \%$ homology to the nucleotide sequence of the gene encoding melastatin-related transient receptor potential member 8 (TRPM8). RT-PCR and Western blot analysis revealed TRPM8 expression in ARpositive, but not AR-negative, prostate cancer cells that was androgen-sensitive, and its levels were significantly higher in urine and blood of prostate cancer patients with metastatic disease as compared to those with localized disease or in healthy men. These studies demonstrate for the first time that TRPM8 mRNA levels in urine and blood may prove to be useful for distinguishing localized prostate cancer from metastatic disease.

\section{Materials and methods}

Surgical specimens. Prostate tissues were obtained from patients undergoing radical prostatectomy at Henry Ford Hospital (HFH). None of these patients received hormonal therapy, chemotherapy or radiation therapy prior to prostatectomy. The tissue procurement protocol for these studies was reviewed and approved by the Institutional Review Board of Henry Ford Hospital. Cancerous tissues were graded by a pathologist according to the Gleason scoring system. Nontumor prostate tissue was obtained from the contralateral lobe of the same specimen. Tumors and patient-matched non-tumor tissues were stored in RNA stabilization solution (Qiagen, Valencia, CA) at $-80^{\circ} \mathrm{C}$ until use.

Blood and urine specimens. Blood and urine specimens were collected from patients undergoing treatment for prostate cancer at Henry Ford Hospital. Blood specimens $(2.5 \mathrm{ml})$ were collected in PAXgene (Qiagen) blood collection tubes with RNA stabilization solution. Urine specimens (10-15 ml) were collected in equal volume of lysis buffer containing $5.64 \mathrm{M}$ guanidinium thiocyanate, $0.5 \%$ sarcosyl, $50 \mathrm{mM}$ sodium acetate $(\mathrm{pH} 6.5)$, and $2 \mathrm{mM}$ B-mercaptoethanol, and the $\mathrm{pH}$ was adjusted to 7.0 with 1.5 M HEPES (pH 8.0). Samples were frozen at $-80^{\circ} \mathrm{C}$ until RNA was extracted. All patients provided written informed consent, and protocols for blood and urine collection for these studies were reviewed and approved by the Institutional Review Board of Henry Ford Hospital.

Cell culture. LNCaP-FGC, BPH1, DU145, PC3, and C4-2B cells were grown in regular RPMI medium (Gibco BRL, Rockville, MD) containing 10\% fetal bovine serum, $2.5 \mathrm{mM}$ glutamine, $100 \mu \mathrm{g} / \mathrm{ml}$ streptomycin, and $100 \mathrm{U} / \mathrm{ml}$ penicillin. Cells were maintained in a humidified incubator with $5 \% \mathrm{CO}_{2}$ and $95 \%$ air at $37^{\circ} \mathrm{C}$.
Steroid deprivation. $\mathrm{LNCaP}$ and C4-2B cells were plated in regular medium and allowed to attach for 24-36 h. Cells were washed once with serum-free RPMI and the medium was then replaced with RPMI supplemented with $10 \%$ charcoaldextran stripped fetal calf serum (CSS). Cells were subjected to two changes of RPMI with CSS over a 6-h period to ensure complete removal of FCS from the plates and grown in CSS containing medium for an additional 40-48 h. Where indicated, $10 \mathrm{nM}$ testosterone was added during the last $8 \mathrm{~h}$ of incubation.

Cell synchronization by isoleucine-deprivation. Synchronization of LNCaP cells using isoleucine-free medium was essentially as described by Cifuentes et al (23). Cells arrested in $\mathrm{G}_{0} / \mathrm{G}_{1}$ phase were released into complete medium containing $10 \%$ FCS and $10 \mathrm{nM}$ testosterone. When the effect of bicalutamide (Casodex) was studied, isoleucine-deprived cells were released into complete medium containing $100 \mu \mathrm{M}$ bicalutamide. The entry of cells into $\mathrm{S}$ phase was determined by pulse labeling the cells with $\left[{ }^{3} \mathrm{H}\right]$-thymidine at regular intervals following release from isoleucine-block.

RNA isolation. Total RNA was extracted from frozen prostate tissue sections and prostate cancer cell lines with RNeasy mini kit (Qiagen) according to the manufacturer's protocols. Total cellular RNA from blood was isolated using PAXgene Blood RNA kit (Qiagen) following the manufacturer's instructions. Total RNA from urine was extracted as described by Menke and Warnecke (17). Residual DNA in total RNA preparations was removed by on-column DNA digestion using RNase-free DNase (Qiagen). The integrity and size distribution of RNA was monitored by agarose gel electrophoresis.

RT-PCR differential display (DD). Total RNA prepared from five tumor and patient-matched non-tumor prostate tissues were subjected to DD analysis using the RNAmp kit (GenHunter, Nashville, TN) as described by Liang and Pardee (15). Reverse transcription of individual RNA samples was performed using SensiScript RT (Qiagen, Santa Clarita, CA). Reverse transcriptase (RT) reactions containing $200 \mathrm{ng}$ of RNA, $2 \mu \mathrm{l}$ of RT, $2 \mu \mathrm{l}$ of 10X RT buffer, $500 \mu \mathrm{M}$ dNTP mix, $1 \mu \mathrm{M}$ anchor primer H-T11C (GenHunter), and $1 \mu \mathrm{l}$ RNase inhibitor $(10 \mathrm{U} / \mu \mathrm{l})$ in a final volume of $20 \mu \mathrm{l}$ were incubated at $37^{\circ} \mathrm{C}$ for $60 \mathrm{~min}$ and then at $94^{\circ} \mathrm{C}$ for $5 \mathrm{~min}$. One-tenth of the $\mathrm{RT}$ reaction mixture was used for PCR. The PCR contained $200 \mathrm{nM}$ each of anchor (H-T11C) and arbitrary (H-AP21) primers (GenHunter), $10 \mathrm{mM}$ Tris- $\mathrm{HCl}, \mathrm{pH} 8.4,50 \mathrm{mM} \mathrm{KCl}$, $1.5 \mathrm{mM} \mathrm{MgCl} 2,5 \mathrm{mM}$ DTT, $2 \mu \mathrm{M}$ dNTP mix, $20 \mathrm{Ci} / \mathrm{mmol}$ $\left[\alpha^{-33} \mathrm{P}\right]-\mathrm{dATP}$ and $2 \mathrm{U}$ of Taq polymerase (Qiagen) in a total volume of $20 \mu \mathrm{l}$. The cycling parameters were 40 cycles of $94^{\circ} \mathrm{C}$ for $15 \mathrm{sec}, 40^{\circ} \mathrm{C}$ for $2 \mathrm{~min}$ and $72^{\circ} \mathrm{C}$ for $30 \mathrm{sec}$ followed by $72^{\circ} \mathrm{C}$ for $5 \mathrm{~min}$. Each PCR was conducted in duplicate to minimize false positives, and PCR products in duplicate samples were subjected to polyacrylamide gel electrophoresis on an extended format using programmable Genomyx LR apparatus (Beckman Corporation). Following autoradiography, differentially expressed cDNA in the gel was retrieved, amplified and cloned into pGEM-T vector (Invitrogen, Carlsbad, $\mathrm{CA}$ ), and clones were confirmed for the presence of the cDNA insert and then sequenced. Gene sequences homologous to 
differentially expressed transcripts were identified by querying GenBank using the BLAST algorithm (18).

Reverse transcription-polymerase chain reaction (RT-PCR). Total RNA isolated from patient samples and prostate cancer cell lines was subjected to semi-quantitative RT-PCR analysis by using cMaster $\mathrm{RT}_{\text {Plus }}$ PCR System (Brinkmann Instruments Inc., Westbury, NY) to determine individual gene mRNA levels. The nucleotide sequences of reverse $(\mathrm{R})$ and forward (F) primers used for PCR amplification of individual genes were as follows: TRPM8-F, 5'-gattttcaccaatgaccgccg and TRPM8-R, 5'-ccccagcagcattgatgtcg (these primers were designed to specifically amplify the RNA fragment that was differentially expressed in tumor vs. patient matched non-tumor prostate tissues and had $100 \%$ homology to the sequence in the TRPM8 gene); AR-F, 5'-tcagttcacttttgacctgctaa and AR-R, 5'-gtggaaatagatgggettga; PSA-F, 5'-gcacccggagagctgtgt and PSA-R: 5'-gatcacgcttttgttcctgat; and GAPDH-F, 5'-gagat ccctccaaaatcaagtg and GAPDH-R, 5'-ccttccacgataccaaagttgt. The primers to amplify TRPM8 from blood and urine were TRPM8-F, 5'-aactaccttgtcaagatcaacaca and TRPM8-R, 5'-ttct caaggtctcagcacactag. A different primer set was used for amplification of TRPM8 in body fluid samples in order to generate a shorter (271 nucleotide long as compared to 503 nucleotide long product with primer set used in tissue samples) RT-PCR product. Different PCR cycle numbers were tested for each gene to ensure that the assay was in the linear range of amplification. PCR products were separated on $2 \%$ agarose gels and mRNA levels were estimated by digital analysis of PCR product band intensity in the gel with an Eagle Eye II still video system, using the EagleSight software (version 3.2; Stratagene, La Jolla, CA). GAPDH mRNA levels were used to normalize test gene mRNA levels in each sample.

Preparation of whole cell extracts. Trypsinized cells were washed once and suspended at a density of $1.5 \times 10^{7}$ cells $/ \mathrm{ml}$ in buffer A (50 mM Tris-HCl, pH 7.4, 0.1\% Triton X-100, 5 mM EDTA, $250 \mathrm{mM} \mathrm{NaCl}, 50 \mathrm{mM} \mathrm{NaF}$, and $0.1 \mathrm{mM} \mathrm{Na}_{3} \mathrm{VO}_{4}$ ) supplemented with protease inhibitor cocktail (P-8340, Sigma Chemical Co., St Louis, MO). They were then subjected to 60 pulses of sonication using a Branson Sonifier 250 (Branson Sonic Power Co., Danbury, CT), set at an output control of 2 and a duty cycle of 20, with intermittent cooling on ice. Sonicated cell extracts were cleared by centrifugation in an Eppendorf centrifuge at $12.5 \mathrm{~K} \mathrm{rpm}$ for $1 \mathrm{~min}$. Protein concentration in cleared extracts was assessed using Bio-Rad Protein Assay reagent (Bio-Rad Laboratories, Hercules, CA).

Western blot analysis. An equal amount of protein in each sample was subjected to denaturing $8 \%$ polyacrylamide gel electrophoresis (SDS-PAGE) and then transferred to nitrocellulose membranes. Individual membranes were probed with monoclonal antibodies against TRPM8 (Abcam, Cambridge, MA), AR, PSA or B-actin (Santa Cruz Biotechnology, Santa Cruz, CA). Immunoreactive bands were developed using horseradish peroxidase conjugated secondary antibodies and SuperSignal WestPico chemiluminescent substrate (Pierce Life Science Co., Rockford, IL) and visualized using X-ray film.

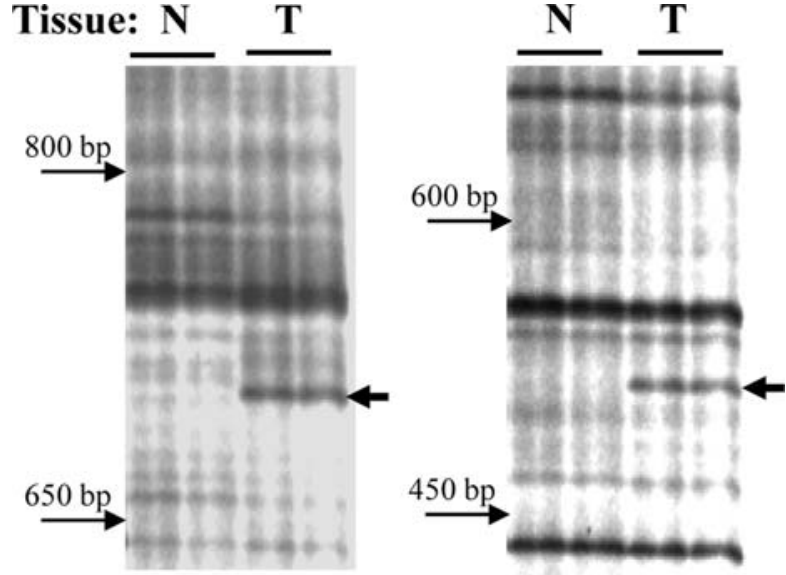

Figure 1. RT-PCR differential display (DD) analysis of prostate cancer and non-tumor tissue: total RNA isolated from tumor (T) and patient-matched prostate non-tumor $(\mathrm{N})$ tissues from 5 patients was subjected to DD analysis as described in Materials and methods. A representative profile of RNA bands generated from total RNA of one of the three patients in whom differential expression of two RNA transcripts (thick arrows) was observed is presented in the figure. Each panel represents separate sections of the same extended gel. Migration of marker oligonucleotides of different lengths $(800,650,600$, and 450 base pair long) on the gel is indicated by thin arrows. Sequencing analysis indicated $100 \%$ sequence homology between RNA in the two differentially expressed bands.

Statistical analysis. One-way ANOVA with Tukey-Kramer multiple comparisons post test was performed using GraphPad Instat version 3.00 for Windows 95, GraphPad Software, San Diego, CA.

\section{Results}

DD analysis of tumor vs. patient-matched non-tumor prostate tissues. Total RNA isolated from tumor and patient-matched non-tumor prostate tissues was subjected to DD analysis to identify genes whose expression in tumors is distinctly different from that in non-tumor tissue. As shown in Fig. 1, we observed two RNA transcripts of $\sim 700$ (left panel) and $\sim 500$ (right panel) nucleotides long that were overexpressed in tumor $(\mathrm{T})$ as compared to patient-matched non-tumor $(\mathrm{N})$ tissues. A similar overexpression of these two RNA transcripts in tumor vs. non-tumor tissues was noted in 3 of the 5 patient samples examined by DD (data not shown). Nucleotide sequence analysis revealed that these two transcripts shared a common sequence (accession no. EH613309) and that this sequence had $100 \%$ homology to the nucleotide sequence in the TRPM8 gene (accession no. NM_024080.3). Thus TRPM8 seems to be overexpressed in tumors as compared to patient-matched nontumor tissues of prostate cancer patients.

RT-PCR analysis of TRPM8 mRNA in prostate tissues of prostatectomy patients. Since TRPM8 related RNA transcript was overexpressed in 3 of the 5 patients examined by DD, we evaluated the prevalence of TRPM8 overexpression in a crosssection patient population. We performed semi-quantitative RT-PCR analysis of tumor and patient-matched non-tumor tissue RNA from 40 patients with Gleason scores ranging from 6 to 9 . Unlike in DD analysis, we used TRPM8 sequencespecific primers in RT-PCR analysis to estimate TRPM8 mRNA levels. Representative RT-PCR products in assays with 
$\mathbf{A}$

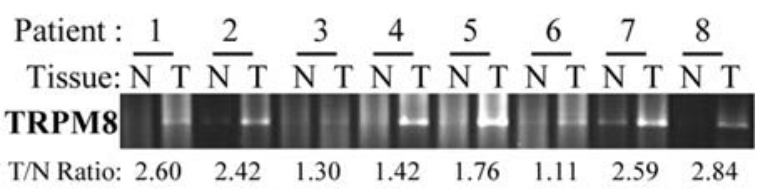

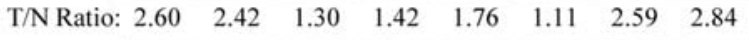

AR

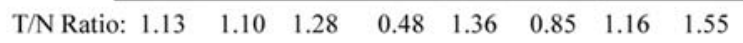

GAPDH

B

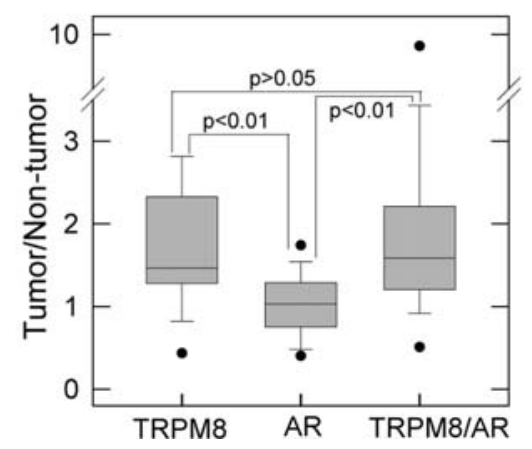

Figure 2. Semi-quantitative RT-PCR analysis of TRPM8 and AR expression in tumor and patient-matched non-tumor prostate tissues: total RNA prepared from tumor $(\mathrm{T})$ and patient-matched non-tumor $(\mathrm{N})$ prostate tissues was subjected to RT-PCR using TRPM8-, AR-, and GAPDH-specific primers as described in Materials and methods. The relative density of GAPDHnormalized TRPM8 and AR bands was determined and the T/N ratio of GAPDH-normalized TRPM8 and AR band densities are presented below the TRPM8 and AR gel images, respectively, of representative patient samples (A). T/N ratios for TRPM8, AR, and TRPM8/AR obtained from RT-PCR analysis of 40 prostate cancer patients representing Gleason grades $3+3,3+4$, $3+5,4+3,4+4$ and $5+4$ are presented in $\mathrm{B}$. The boxes show median and intraquartite values. Closed circles outside the whisker-box plots represent $5 / 95$ th percentile points.

tumor and non-tumor RNA from 8 patients are shown in Fig. 2A. We observed GAPDH-normalized TRPM8 overexpression in tumors as compared to non-tumor tissue from 31 of the 40 patients. The mean tumor to non-tumor $(\mathrm{T} / \mathrm{N})$ ratio of the GAPDH-normalized TRPM8 mRNA level was $1.94 \pm 0.256(n=40)$ (Fig. 2B). However, no significant relationship between Gleason score and T/N ratio of TRPM8 mRNA level was observed in this patient population (data not shown). Thus TRPM8 overexpression was observed in $>75 \%$ of patients examined and was independent of Gleason score.

TRPM8 overexpression is independent of AR mRNA levels in prostate tissues. TRPM8 expression is reported to be androgen regulated in prostate cancer cells (19-21). Therefore we examined whether the increase in TRPM8 levels in prostate tumor tissues is associated with a corresponding increase in androgen receptor (AR) expression. A profile of RT-PCR products generated using AR-specific primers in reactions with RNA from tumor and patient-matched non-tumor prostate tissues from 8 patients is shown Fig. 2A. These analyses revealed no significant difference in GAPDH-normalized AR mRNA levels between tumor (T) and patient-matched non-tumor $(\mathrm{N})$ tissues. The mean of $\mathrm{T} / \mathrm{N}$ ratio of $\mathrm{GAPDH}-$ normalized AR was $1.05 \pm 0.08(n=40)$ (Fig. 2B). Thus, in

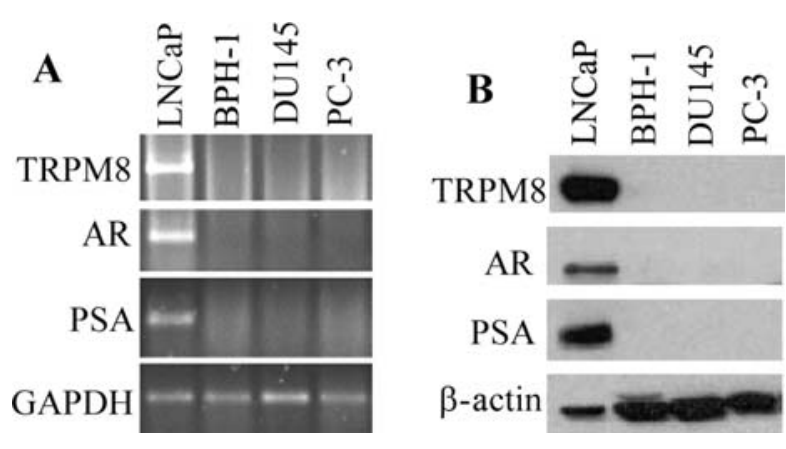

Figure 3. Expression of TRPM8 in prostate cancer cell lines: total RNA or whole cell extracts prepared from exponentially growing LNCaP, BPH-1, DU145, and PC-3 cells were subjected to RT-PCR (A) or Western blot analysis (B), respectively to determine TRPM8, AR, and PSA expression as described in Materials and methods.

prostate tumors, the increase in TRPM8 levels was not associated with an increase in AR mRNA levels. Therefore, TRPM8 levels expressed as a ratio of TRPM8/AR were significantly higher $(1.96 \pm 0.237$-fold, $n=40)$ in tumors than in patient-matched non-tumor tissues of prostate cancer patients (Fig. 2B).

$A R$ is required for TRPM8 expression in prostate cancer cell lines. Since we found no association between TRPM8 and AR mRNA levels in prostate tumor tissues, we tested whether TRPM8 expression requires AR expression in prostate cancer cells. We studied the expression of TRPM8, AR and PSA in AR-positive and AR-negative prostate cancer cell lines. PSA was included in these studies to serve as a positive control for AR regulated gene expression. As shown in Fig. 3A, TRPM8 mRNA as well as PSA mRNA expression was noticeable in AR-positive LNCaP cells but not in AR-negative DU145, PC-3 or BPH-1 cells. Western blot analysis confirmed that TRPM8 and PSA proteins were expressed only in AR-positive LNCaP cells (Fig. 3B). Thus, TRPM8 expression seemed to depend on the expression of AR in prostate cancer cells.

Anti-androgen bicalutamide (Casodex) attenuates TRPM8 expression in LNCaP cells. Since TRPM8 was expressed only in AR-positive cells, we studied whether AR activity is required for TRPM8 expression. Casodex, an anti-androgen, is known to inhibit AR activity and also decrease AR protein levels in prostate cancer cells. As shown in Fig. 4, Casodex treatment resulted in a 52 and $71 \%$ decrease in TRPM8 mRNA (Fig. 4A) and protein (Fig. 4B) levels, respectively. This decrease in TRPM8 levels was associated with a corresponding decrease in AR mRNA (Fig. 4A) and protein (Fig. 4B) levels. Thus, Casodex inhibited the expression of TRPM8 at both mRNA and protein levels, supporting a role of AR in TRPM8 expression in $\mathrm{LNCaP}$ cells.

Testosterone induces TRPM8 expression in prostate cancer cells. To further evaluate a role of AR in TRPM8 expression, we studied the effect of testosterone on TRPM8 expression in hormone-deprived androgen-sensitive $\mathrm{LNCaP}$ and androgenindependent C4-2B cells. As shown in Fig. 4, hormonedeprivation by incubating cells in charcoal-stripped serum (CSS)-containing medium for $40 \mathrm{~h}$ resulted in a dramatic 
$\mathbf{A}$

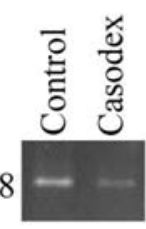

TRPM8

TRPM8/GAPDH: $1.0 \quad 0.48$

$\mathrm{AR}$

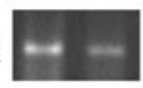

AR/GAPDH: $1.0 \quad 0.64$

GAPDH

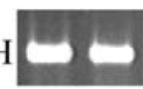

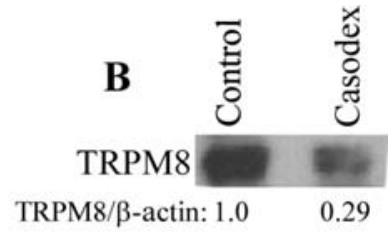

AR

AR/ $\beta$-actin: $1.0 \quad 0.45$

$\beta$-actin

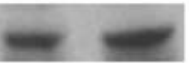

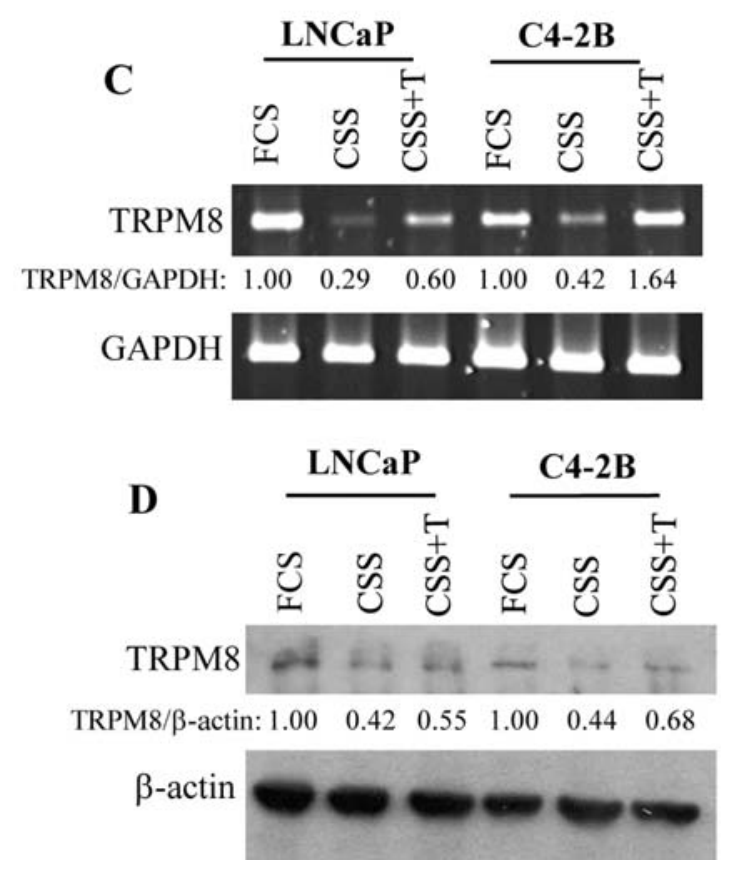

Figure 4. AR activity is required for TRPM8 expression in prostate cancer cells. Effect of Casodex on the expression of TRPM8 and AR: LNCaP cells were treated with $100 \mu \mathrm{M}$ bicalutamide (Casodex) for $24 \mathrm{~h}$ and the total RNA and whole cell extracts prepared from control (vehicle treated) and Casodex treated cells were subjected to RT-PCR (A) and Western blot analysis (B), respectively, to determine TRPM8 and AR levels as described in Materials and methods. Relative densities of TRPM8 and AR bands normalized to the density of GAPDH (RT-PCR) or B-actin (Western blotting) bands in control and Casodex treated samples are presented below the TRPM8 and AR gels, respectively. Effect of androgen-deprivation on the expression of TRPM8: exponentially growing LNCaP and $\mathrm{C} 4-2 \mathrm{~B}$ cells in complete media were hormone-deprived by growing in RPMI medium containing charcoal stripped FCS for $40 \mathrm{~h}$. Hormone-deprived cells were then treated with testosterone for $8 \mathrm{~h}$. Total RNA and whole cell extracts prepared from control (FCS), hormone-deprived (CSS) and testosterone treated (CSS+T) cells were subjected to RT-PCR (C) and Western blot analysis (D), respectively, to determine TRPM8 levels as described in Materials and methods. Relative densities of TRPM8 bands normalized to the density of GAPDH (RT-PCR) or $\beta$-actin (Western blotting) bands are presented below the TRPM8 gels.

decrease in TRPM8 at both mRNA (Fig. 4C) and protein (Fig. 4D) levels. Addition of testosterone alone to CSScontaining media for $8 \mathrm{~h}$ after a 40-h hormone-deprivation restored TRPM8 mRNA expression to 60 and 164\% of control level in LNCaP and C4-2B cells, respectively (Fig. 4C). During the same 8-h period there was also a modest increase of TRPM8 protein in both LNCaP and C4-2B cells (Fig. 4D), indicating that testosterone-induced restoration of TRPM8 protein requires longer treatment with testosterone than is
A

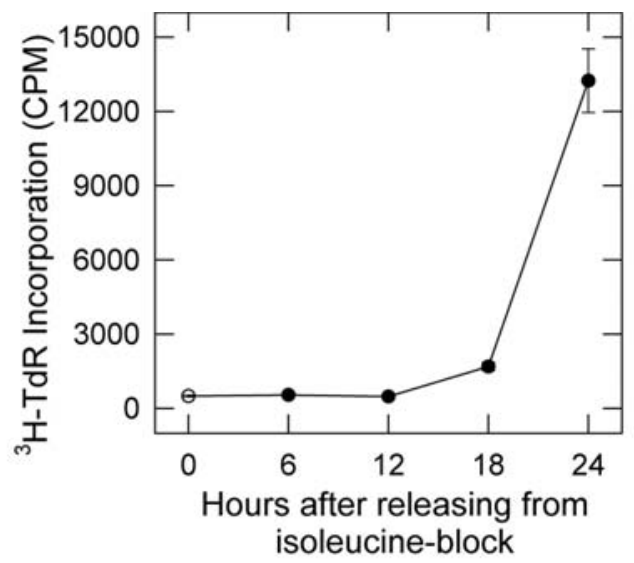

B

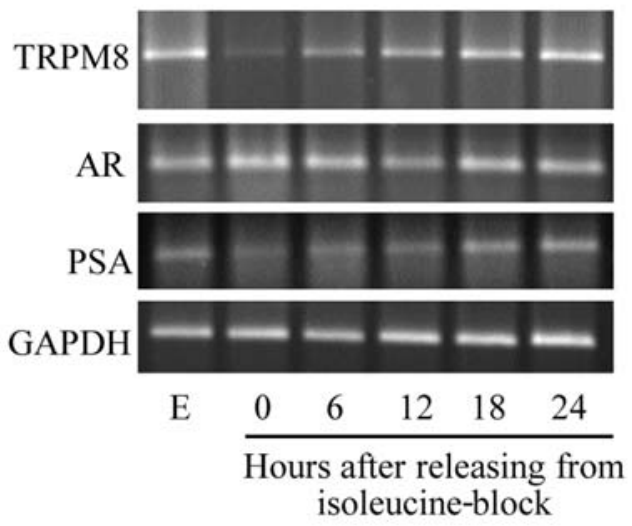

C

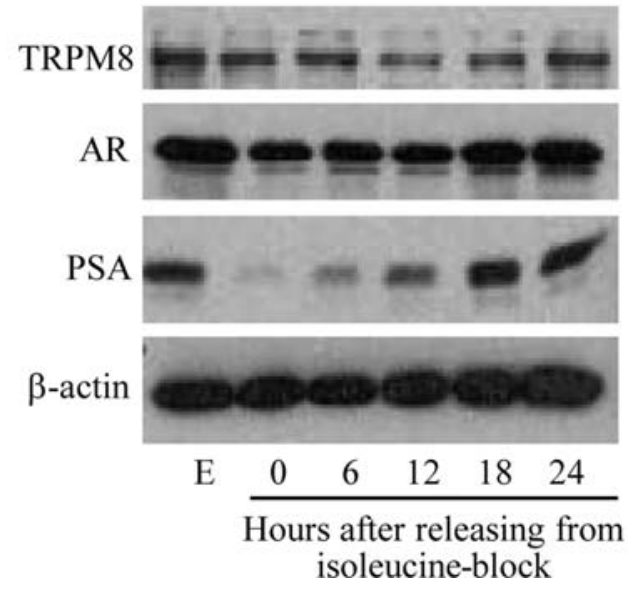

Figure 5. Expression of TRPM8, AR and PSA in synchronized LNCaP cells progressing from $\mathrm{G}_{0} / \mathrm{G}_{1}$ to $\mathrm{S}$ phase. Exponentially growing $\mathrm{LNCaP}$ cells synchronized by isoleucine-deprivation were released into complete media. At 6-h intervals after releasing from isoleucine-block, cells were pulse-labeled with $\left[{ }^{3} \mathrm{H}\right]$-thymidine $\left({ }^{3} \mathrm{H}-\mathrm{TdR}\right)$ and the incorporation of ${ }^{3} \mathrm{H}-\mathrm{TdR}$ into DNA was measured to monitor the progression of cells from $\mathrm{G}_{1}$ to $\mathrm{S}$ phase (A). Total RNA and whole cell extracts prepared at the same intervals were subjected to RT-PCR (B) and Western blot analysis (C), respectively, to determine TRPM8, AR, and PSA levels as described in Materials and methods. E, exponentially growing cells.

required for the restoration of its mRNA. Thus in androgensensitive as well as androgen-independent cell lines, expression of TRPM8 was attenuated by steroid deprivation and was restored by testosterone, indicating that TRPM8 expression is androgen regulated in prostate cancer cells.

TRPM8 mRNA expression is increased in synchronized LNCaP cells progressing from $G_{l}$ to $S$ phase. At present, the role of 

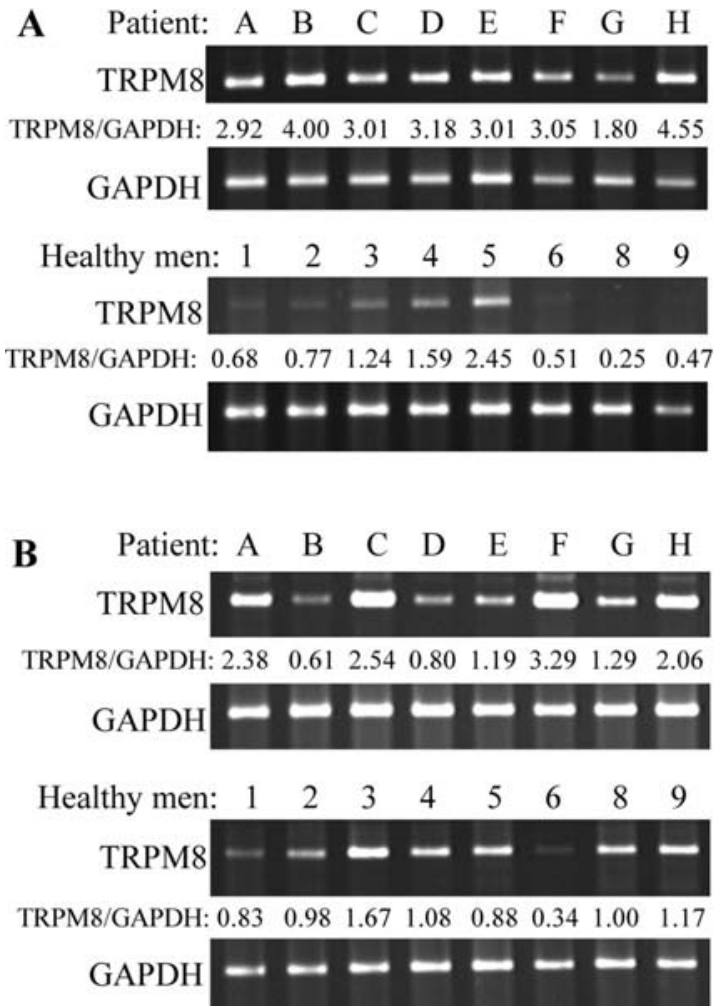

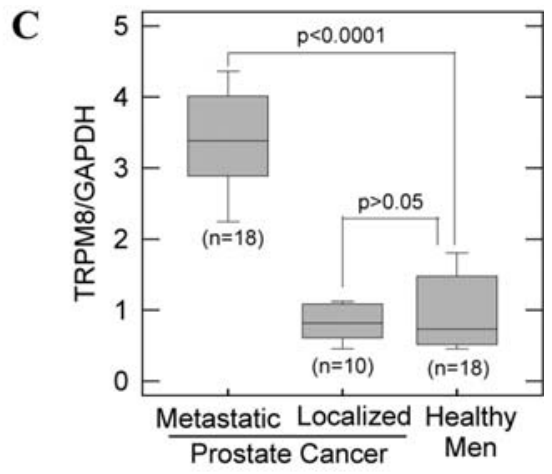

D

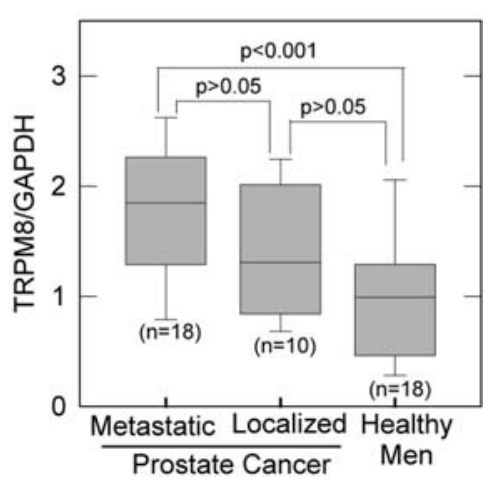

Figure 6. RT-PCR analysis of TRPM8 in urine and blood samples of prostate cancer patients and healthy men: total RNA prepared from urine and blood of prostate cancer patients with metastatic or localized disease and healthy men were subjected to RT-PCR using TRPM8-specific primers as described in Materials and methods. A representative profile of RT-PCR products of TRPM8 and GAPDH in urine (A) and blood (B) samples from metastatic prostate cancer patients and healthy men are shown. GAPDH-normalized TRPM8 levels based on individual band densities are presented below the TRPM8 gels. Whisker plots showing GAPDH-normalized TRPM8 levels in urine (C) and blood (D) samples from metastatic and localized prostate cancer patients and healthy men are shown. The data shown in $\mathrm{C}$ and $\mathrm{D}$ are pooled from two separate experiments and the GAPDH-normalized TRPM8 levels in each experiment were normalized to the mean GAPDH-normalized TRPM8 level in healthy men.

TRPM8 in prostate cancer cells is not clear. Since AR plays an important role in LNCaP cell proliferation $(22,23)$, we tested whether androgen/AR regulated TRPM8 expression is associated with the progression of prostate cancer cells from $G_{1}$ to $\mathrm{S}$ phase. We employed isoleucine-deprivation to reversibly block LNCaP cells in $\mathrm{G}_{0} / \mathrm{G}_{1}$ phase (23). Cells released from isoleucine-block progressed synchronously from $\mathrm{G}_{1}$ to $\mathrm{S}$ phase (Fig. 5A). TRPM8 mRNA expression decreased dramatically in cells arrested in $G_{0} / G_{1}$ phase and increased gradually as the cells progressed towards $\mathrm{S}$ phase after releasing from isoleucine-block (Fig. 5B). A similar trend was observed for PSA mRNA expression in cells progressing from $G_{1}$ to $S$ phase (Fig. 5B). This change in expression levels of TRPM8 and PSA was independent of changes in AR mRNA levels. AR mRNA levels remained relatively the same in cells arrested in $G_{0} / G_{1}$ phase and in those progressing from $G_{1}$ to $S$ phase (Fig. 5B). However, there was a noticeable decrease in AR protein levels in cells arrested in $G_{0} / G_{1}$ phase and $A R$ protein increased as cells released from isoleucine-block entered $S$ phase (Fig. 5C). This increase in AR protein levels during the progression of cells from $\mathrm{G}_{1}$ to $\mathrm{S}$ phase was associated with a noticeable increase in TRPM8 protein (Fig. 5C). By comparison, PSA protein levels showed a remarkable increase during the same period (Fig. 5C). Thus, the increase in TRPM8 and PSA protein levels coincided with the increase in AR protein levels during progression of synchronized $\mathrm{LNCaP}$ cells from $\mathrm{G}_{1}$ to $\mathrm{S}$ phase.
TRPM8 mRNA levels are elevated in body fluids of patients with metastatic prostate cancer. In an attempt to determine whether the overexpression of TRPM 8 mRNA observed in tumor tissues can be found in body fluids of patients with prostate cancer, we performed semi-quantitative RT-PCR analysis of total RNA isolated from urine and blood of healthy men (controls) and patients with clinically localized prostate cancer (patients undergoing radical prostatectomy) or metastatic disease (patients undergoing chemotherapy for advanced disease). TRPM8 mRNA was readily detectable in urine (Fig. 6A) as well as blood (Fig. 6B) samples from patients as well as healthy men. Interestingly, while TRPM8 mRNA levels in urine and blood of patients with localized cancer were not significantly different $(\mathrm{p}>0.05, \mathrm{n}=10)$ from those in healthy men, levels were significantly higher $(\mathrm{p}<0.001, \mathrm{n}=18)$ in urine and blood of patients with metastatic disease than in those of healthy men (Fig. 6C and D). In urine samples (Fig. 6C), TRPM8 mRNA levels were 3- to 4-fold higher in patients with metastatic disease (mean $3.37 \pm 0.176, \mathrm{n}=18$ ) than in those with localized prostate cancer (mean $0.82 \pm 0.075, \mathrm{n}=10$ ) or in healthy men (mean 1.0 $\pm 0.141, \mathrm{n}=18$ ). By comparison, TRPM8 mRNA levels in the blood of patients with metastatic disease (mean $1.81 \pm 0.153, \mathrm{n}=18)$ were significantly higher $(\mathrm{p}<0.001)$ than in healthy men (mean $1.0 \pm 0.132, \mathrm{n}=18$ ), but were not significantly higher $(\mathrm{p}>0.05)$ than in patients with localized prostate cancer

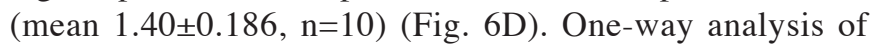
variance (ANOVA) revealed $\mathrm{p}<0.0001$ for urine and $\mathrm{p}=0.0008$ for blood samples, indicating that the variation among these 
3 groups of men was significantly greater than the variation within each group. These observations raise the possibility that, while TRPM8 mRNA levels in tissue specimens can be used for the detection of prostate cancer, its increased presence in body fluids, particularly in urine, may signal prostate cancer metastasis.

\section{Discussion}

RT-PCR differential display (15) analysis led to the identification of two RNA transcripts that were overexpressed in tumor vs. patient-matched non-tumor tissues from 3 of the 5 patients examined. These RNA transcripts showed 100\% homology to TRPM8 gene sequence and semi-quantitative RT-PCR analysis using TRPM8 gene-specific primers revealed TRPM8 overexpression in tumor tissues from $>75 \%$ of patients. Most importantly, these studies demonstrated for the first time that TRPM8 mRNA can be assayed in urine and blood, and that TRPM8 mRNA levels are significantly higher in these body fluids of patients with metastatic, but not localized, prostate cancer than in healthy men. In addition, TRPM8 is shown to be expressed in AR-positive, but not in AR-negative, prostate cancer cells in an androgen-dependent manner, and its expression increases as AR-positive cells progress from $\mathrm{G}_{1}$ to $\mathrm{S}$ phase. These latter observations raise the possibility that TRPM8 may play role in androgen/AR regulated proliferation of prostate cancer cells.

Previously, we (24) and others (19,20,25-27) reported differential expression of TRPM8 in tumor vs. non-tumor tissues of prostate cancer patients. By subjecting a cDNA library prepared from human prostate mRNA to subtractive hybridization, Tsavaler et al (19) found prostate to be the only tissue, besides sensory neurons, in which TRPM8 is detected at a high level. In situ hybridization studies indicated a varied expression of TRPM8 ranging from moderate in normal, moderate to high in benign prostatic hyperplasia (BPH) and high in prostate cancer tissues (19). Semi-quantitative RT-PCR analysis of RNA in the present study showed no significant variation in tumor/non-tumor $(\mathrm{T} / \mathrm{N})$ ratio of TRPM8 mRNA levels in tissues representing different Gleason scores (data not shown). This lack of correlation between TRPM8 expression and severity of the disease was due to a noticeable variability in $\mathrm{T} / \mathrm{N}$ ratios among tissues with the same Gleason score, an observation consistent with the report of Kiessling et al (26). Although in situ hybridization indicated moderate to high expression of TRPM8 in prostate tissue of BPH patients (19), BPH-1 cells that lack AR and are derived from human BPH tissue (28) showed no evidence of TRPM8 expression (Fig. 3). Since TRPM8 expression is reported to be androgen/ARdependent $(20,21)$, it is not clear whether the BPH cell types that are TRPM8-positive based on in situ hybridization (19) express AR. Additional studies employing more sensitive and specific assays are needed to determine selective overexpression of TRPM8 in BPH.

Patients with a negative biopsy despite an elevated serum PSA and patients with low risk prostate cancer may be monitored by annual prostate biopsy $(7,29)$. Repeat biopsy procedures may be associated with complications such as infection and urinary retention (8). Thus, there is an urgent need for non-invasive, sensitive and specific biomarkers that can be used either alone or in combination with PSA to accurately diagnose prostate cancer that needs to be treated. Therefore, in order to have widespread applicability a biomarker should be detectable in easily obtainable body fluids such as urine or blood, and should possibly be able to distinguish localized prostate cancer from metastatic disease. Some genes that are expressed at higher than normal levels in prostate cancer tissue $(30,31)$ are also found to be elevated in patient urine and blood (24,30,32-35). Our observation that TRPM8 mRNA levels are significantly higher in urine and blood of patients with metastatic disease than in healthy men (Fig. 6) suggests potential usefulness of TRPM8 mRNA levels in body fluids as a prognostic indicator of metastatic prostate cancer. Patients with metastatic hormone-refractory disease had had a radical prostatectomy or radiation therapy. TRPM 8 mRNA detected in body fluids may have derived from circulating tumor cells. In patients with localized disease, circulating tumor cells may not be present in sufficient number to generate enough TRPM8 mRNA for it to be detected by RT-PCR in body fluids. This difference in TRPM8 levels between patients with metastatic disease and localized prostate cancer may help in determining an appropriate treatment for prostate cancer.

Using the prostate cancer xenograft model, it is reported that TRPM8 expression is lost when the growth of tumors derived from androgen-dependent LuCaP-35 cells transit to androgen-independence (25). However, in the present study we observed that androgen-independent $\mathrm{C} 4-2 \mathrm{~B}$ cells, which are derived from a similar xenograft model of androgendependent LNCaP cells (36), continued to express TRPM8 at both the mRNA and protein level, and also this was androgen-dependent (Fig. 4C and D). These observations indicate that androgen-independent growth may effect TRPM8 expression differently in different tumors.

Although TRPM8 expression requires functional AR and several putative androgen-responsive elements (AREs) are reported to be present in the TRPM8 promoter region (21), its role in prostate cancer development or progression remains unknown. TRPM8 is a member of the transient receptor potential (TRP) family of $\mathrm{Ca}^{++}$-permeable non-selective cation channels and is known to serve as a cold and pain sensor in sensory neurons $(37,38)$. Immunofluorescence studies showed TRPM8 localization in plasma membrane as well as endoplasmic reticulum, implicating its role in regulation of intracellular $\mathrm{Ca}^{++}$and $\mathrm{Na}^{+}$levels necessary for proliferation and viability of prostate cancer cells $(20,39,40)$. Consistent with this possibility, we observed an increase in TRPM8 expression as synchronized $\mathrm{G}_{1}$ phase $\mathrm{LNCaP}$ cells entered $\mathrm{S}$ phase. This increase in TRPM8 expression was associated with an increase in AR levels (Fig. 5), and possibly also with an increase in AR activity as indicated by the increased expression of PSA during this period (Fig. 5). We reported previously that inhibition of AR activity with Casodex prevents LNCaP cells from entering $S$ phase $(22,23)$. In the present study we observed that Casodex also suppressed TRPM8 expression in LNCaP cells (Fig. 4A and D). Furthermore, $\mathrm{Ca}^{++}$plays an important role in androgen/ AR stimulated proliferation of prostate cancer cells $(41,42)$. Taken together, these observations raise an intriguing possibility that androgen/AR regulated TRPM8 expression may play an important role in raising intracellular $\mathrm{Ca}^{++}$necessary for ARdependent transition of prostate cancer cells from $\mathrm{G}_{1}$ to $\mathrm{S}$ phase. 
In conclusion, these studies are the first to demonstrate elevated TRPM8 mRNA levels in body fluids of prostate cancer patients with metastatic prostate cancer. Extension of these observations to a larger population of patients may lead to the establishment of TRPM8 mRNA as a biomarker for distinguishing localized prostate cancer from metastatic disease. In addition, these studies are the first to report cell cycle-dependent expression of TRPM8 in LNCaP cells progressing from $\mathrm{G}_{1}$ to $\mathrm{S}$ phase. These observations are consistent with a role of TRPM8 in androgen/AR regulated proliferation of prostate cancer cells. Therefore, targeting TRPM8 expression or activity in prostate cancer cells may prove to be an effective strategy for the treatment of prostate cancer.

\section{Acknowledgements}

This study was supported by Vattikuti Urology Institute.

\section{References}

1. Jemal A, Siegel R, Ward E, Murray T, Xu J and Thun MJ: Cancer statistics, 2007. CA Cancer J Clin 57: 43-66, 2007.

2. Yatani R, Chigusa I, Akazaki K, Stemmermann GN, Welsh RA and Correa P: Geographic pathology of latent prostatic carcinoma. Int J Cancer 29: 611-616, 1982.

3. Zimmerman RA and Culkin DJ: Clinical strategies in the management of biochemical recurrence after radical prostatectomy. Clin Prostate Cancer 2: 160-166, 2003.

4. Catalona WJ, Smith DS, Ratliff TL, et al: Measurement of prostate-specific antigen in serum as a screening test for prostate cancer. N Engl J Med 324: 1156-1161, 1991.

5. Thompson IM, Pauler DK, Goodman PJ, et al: Prevalence of $<$ or = 4.0 ng per milliliter. N Engl J Med 350: 2239-2246, 2004.

6. Andriole GL, Grubb RL III, Buys SS, et al: Mortality results from a randomized prostate-cancer screening trial. N Engl J Med 360: 1310-1319, 2009.

7. Klotz L: Active surveillance with selective delayed intervention is the way to manage 'good-risk' prostate cancer. Nat Clin Pract Urol 2: 136-142, 2005.

8. Raja J, Ramachandran N, Munneke G and Patel U: Current status of transrectal ultrasound-guided prostate biopsy in the diagnosis of prostate cancer. Clin Radiol 61: 142-153, 2006.

9. Tomlins SA, Rubin MA and Chinnaiyan AM: Integrative biology of prostate cancer progression. Annu Rev Pathol 1: 243-271, 2006.

10. Chen CD, Welsbie DS, Tran C, et al: Molecular determinants of resistance to antiandrogen therapy. Nat Med 10: 33-39, 2004.

11. Vanpoucke G, Orr B, Grace OC, et al: Transcriptional profiling of inductive mesenchyme to identify molecules involved in prostate development and disease. Genome Biol 8: R213, 2007.

12. Paris PL, Andaya A, Fridlyand J, et al: Whole genome scanning identifies genotypes associated with recurrence and metastasis in prostate tumors. Hum Mol Genet 13: 1303-1313, 2004.

13. Demichelis F, Fall K, Perner S, et al: TMPRSS2:ERG gene fusion associated with lethal prostate cancer in a watchful waiting cohort. Oncogene 26: 4596-4599, 2007.

14. Bismar TA, Demichelis F, Riva A, et al: Defining aggressive prostate cancer using a 12-gene model. Neoplasia 8: 59-68, 2006.

15. Liang P and Pardee AB: Differential display. A general protocol. Mol Biotechnol 10: 261-267, 1998

16. Martin KJ, Graner E, Li Y, et al: High-sensitivity array analysis of gene expression for the early detection of disseminated breast tumor cells in peripheral blood. Proc Natl Acad Sci USA 98: 2646-2651, 2001.

17. Menke TB and Warnecke JM: Improved conditions for isolation and quantification of RNA in urine specimens. Ann NY Acad Sci 1022: 185-189, 2004.

18. Altschul SF, Madden TL, Schaffer AA, et al: Gapped BLAST and PSI-BLAST: a new generation of protein database search programs. Nucleic Acids Res 25: 3389-3402, 1997.

19. Tsavaler L, Shapero MH, Morkowski S and Laus R: Trp-p8, a novel prostate-specific gene, is up-regulated in prostate cancer and other malignancies and shares high homology with transient receptor potential calcium channel proteins. Cancer Res 61: 3760-3769, 2001.
20. Zhang L and Barritt GJ: Evidence that TRPM8 is an androgendependent $\mathrm{Ca}^{2+}$ channel required for the survival of prostate cancer cells. Cancer Res 64: 8365-8373, 2004.

21. Bidaux G, Roudbaraki M, Merle C, et al: Evidence for specific TRPM8 expression in human prostate secretory epithelial cells: functional androgen receptor requirement. Endocr Relat Cancer 12: 367-382, 2005.

22. Bai VU, Cifuentes E, Menon M, Barrack ER and Reddy GP: Androgen receptor regulates $\mathrm{Cdc} 6$ in synchronized $\mathrm{LNCaP}$ cells progressing from G1 to S phase. J Cell Physiol 204: 381-387, 2005.

23. Cifuentes E, Croxen R, Menon M, Barrack ER and Reddy GP: Synchronized prostate cancer cells for studying androgen regulated events in cell cycle progression from $\mathrm{G} 1$ into $\mathrm{S}$ phase. J Cell Physiol 195: 337-345, 2003.

24. Bai VU, Kaseb A, Tejwani S, et al: Identification of prostate cancer mRNA markers by averaged differential expression and their detection in biopsies, blood, and urine. Proc Natl Acad Sci USA 104: 2343-2348, 2007.

25. Henshall SM, Afar DE, Hiller J, et al: Survival analysis of genome-wide gene expression profiles of prostate cancers identifies new prognostic targets of disease relapse. Cancer Res 63: 4196-4203, 2003.

26. Kiessling A, Fussel S, Schmitz M, et al: Identification of an HLA-A 0201 -restricted T-cell epitope derived from the prostate cancer-associated protein trp-p8. Prostate 56: 270-279, 2003.

27. Fuessel S, Sickert D, Meye A, et al: Multiple tumor marker analyses (PSA, hK2, PSCA, trp-p8) in primary prostate cancers using quantitative RT-PCR. Int J Oncol 23: 221-228, 2003.

28. Hayward SW, Dahiya R, Cunha GR, Bartek J, Deshpande N and Narayan P: Establishment and characterization of an immortalized but non-transformed human prostate epithelial cell line: BPH-1. In Vitro Cell Dev Biol 31: 14-24, 1995.

29. Carter HB, Walsh PC, Landis P and Epstein JI: Expectant management of nonpalpable prostate cancer with curative intent: preliminary results. J Urol 167: 1231-1234, 2002.

30. Chatterjee SK and Zetter BR: Cancer biomarkers: knowing the present and predicting the future. Future Oncol 1: 37-50, 2005.

31. Tricoli JV, Schoenfeldt M and Conley BA: Detection of prostate cancer and predicting progression: current and future diagnostic markers. Clin Cancer Res 10: 3943-3953, 2004.

32. Hutchinson LM, Chang EL, Becker CM, et al: Use of thymosin beta 15 as a urinary biomarker in human prostate cancer. Prostate 64: 116-127, 2005.

33. Hutchinson LM, Chang EL, Becker CM, et al: Development of a sensitive and specific enzyme-linked immunosorbent assay for thymosin beta15, a urinary biomarker of human prostate cancer. Clin Biochem 38: 558-571, 2005.

34. Mearini E, Antognelli C, Del Buono C, et al: The combination of urine DD3(PCA3) mRNA and PSA mRNA as molecular markers of prostate cancer. Biomarkers 14: 235-243, 2009.

35. Tomlins SA, Bjartell A, Chinnaiyan AM, et al: ETS gene fusions in prostate cancer: from discovery to daily clinical practice. Eur Urol 56: 275-286, 2009.

36. Thalmann GN, Anezinis PE, Chang SM, et al: Androgenindependent cancer progression and bone metastasis in the LNCaP model of human prostate cancer. Cancer Res 54: 2577-2581, 1994.

37. Story GM, Peier AM, Reeve AJ, et al: ANKTM1, a TRP-like channel expressed in nociceptive neurons, is activated by cold temperatures. Cell 112: 819-829, 2003.

38. McKemy DD: How cold is it? TRPM8 and TRPA1 in the molecular logic of cold sensation. Mol Pain 1: 16, 2005.

39. Thebault S, Lemonnier L, Bidaux G, et al: Novel role of cold/ menthol-sensitive transient receptor potential melastatine family member 8 (TRPM8) in the activation of store-operated channels in LNCaP human prostate cancer epithelial cells. J Biol Chem 280: 39423-39435, 2005.

40. Bidaux G, Flourakis M, Thebault S, et al: Prostate cell differentiation status determines transient receptor potential melastatin member 8 channel subcellular localization and function. J Clin Invest 117: 1647-1657, 2007.

41. Reddy GP, Barrack ER, Dou QP, et al: Regulatory processes affecting androgen receptor expression, stability, and function: potential targets to treat hormone-refractory prostate cancer. J Cell Biochem 98: 1408-1423, 2006.

42. Nantermet PV, Xu J, Yu Y, et al: Identification of genetic pathways activated by the androgen receptor during the induction of proliferation in the ventral prostate gland. J Biol Chem 279: 1310-1322, 2004. 